\title{
Exercise-induced pulmonary hemorrhage: where are we now?
}

\author{
David C Poole ${ }^{1,2}$ \\ Howard H Erickson' \\ 'Department of Anatomy and \\ Physiology, ${ }^{2}$ Department of \\ Kinesiology, College of Veterinary \\ Medicine, Kansas State University, \\ Manhattan, KS, USA
}

This article was published in the following Dove Press journal:

Veterinary Medicine: Research and Reports

7 November 2016

Number of times this article has been viewed

\begin{abstract}
As the Thoroughbreds race for the final stretch, 44 hooves flash and thunder creating a cacophony of tortured air and turf. Orchestrated by selective breeding for physiology and biomechanics, expressed as speed, the millennia-old symphony of man and beast reaches its climax. At nearly 73 kilometers per hour ( $45 \mathrm{mph}$ ) over half a ton of flesh and bone dwarfs its limpet-like jockey as, eyes wild and nostrils flaring, their necks stretch for glory. Beneath each resplendent livery-adorned, latherin-splattered coat hides a monstrous heart trilling at 4 beats per second, and each minute, driving over $400 \mathrm{~L}$ (105 gallons) of oxygen-rich blood from lungs to muscles. Matching breath to stride frequency, those lungs will inhale $16 \mathrm{~L}$ (4 gallons) of air each stride moving $>1,000 \mathrm{~L} / \mathrm{min}$ in and out of each nostril - and yet failing. Engorged with blood and stretched to breaking point, those lungs can no longer redden the arterial blood but leave it dusky and cyanotic. Their exquisitely thin blood-gas barrier, a mere $10.5 \mu \mathrm{m}$ thick (1/50,000 of an inch), ruptures, and red cells invade the lungs. After the race is won and lost, long after the frenetic crowd has quieted and gone, that blood will clog and inflame the airways. For a few horses, those who bleed extensively, it will overflow their lungs and spray from their nostrils incarnadining the walls of their stall: a horrifically poignant canvas that strikes at horse racing's very core. That exercise-induced pulmonary hemorrhage (EIPH) occurs is a medical and physiological reality. That every reasonable exigency is not taken to reduce/prevent it would be a travesty. This review is not intended to provide an exhaustive coverage of EIPH for which the reader is referred to recent reviews, rather, after a brief reminder of its physiologic and pathologic bases, focus is brought on the latest developments in EIPH discovery as this informs state-of-the-art knowledge, the implementation of that knowledge and recommendations for future research and treatment.
\end{abstract}

Keywords: epistaxis, Thoroughbred racehorse, pulmonary capillary rupture, vascular pressure, alveolar pressure, nasal airway collapse

\section{Background}

Exercise-induced pulmonary hemorrhage (EIPH) is diagnosed most commonly in the racehorse, ${ }^{1-7}$ but also occurs in Greyhounds ${ }^{8}$ and healthy human athletes ${ }^{9}$ as well as in patients with diseases such as left heart failure which elevate pulmonary vascular pressures. ${ }^{5}$ Other human endeavors such as prolonged saxophone playing may also induce alveolar hemorrhage. ${ }^{10}$ In horses, the 2015 American College of Veterinary Internal Medicine Consensus Statement made the strong recommendation that EIPH be considered as a disease rather than a "condition". ${ }^{7}$ The necessary conditions for EIPH in the healthy exercising horse consist of high pulmonary capillary transmural pressures, the product of a prodigious cardiac output, combined with very negative
Correspondence: David C Poole Department of Anatomy and Physiology, College of Veterinary Medicine, Kansas State University, Manhattan, KS 66506, USA

Tel +l 7855324529

Email poole@vet.ksu.edu 
alveolar pressures that summate across the exquisitely thin intervening blood-gas barrier. EIPH occurs primarily in Thoroughbreds, Quarter Horses and Standardbreds and during sprint racing. EIPH is also apparent across other high-performance equine athletes, including cutting, reining, barrel, roping, polo, cross-country and 3-day event, show jumping, hunter-jumper, steeplechase, dressage and draft horses. ${ }^{6,7,11}$ Indeed, even sustained submaximal exercise induces EIPH. ${ }^{12}$ EIPH is a substantial problem for the horse racing industry for multiple reasons that include decreased performance,${ }^{6}$ lost training days, necessity for pre-race medication, banning of horses from racing, occasional death, ${ }^{13,14}$ and public perception. ${ }^{1,6,15}$ Moreover, EIPH constitutes a critical basis for exercise intolerance and progressively damages a horse's lungs in proportion to its lifetime starts and training history. ${ }^{1,16-19}$ Horses with either no or mild bleeding have a 4-fold higher chance of winning a race as their counterparts with moderate or severe EIPH. ${ }^{6,15,19}$

Epistaxis, bleeding from the nostrils, is the most visible form of EIPH (Figure 1). This condition has been recognized at least since Elizabethan times. For instance, Gervase Markham's “Masterpiece” described bleeding after exercise

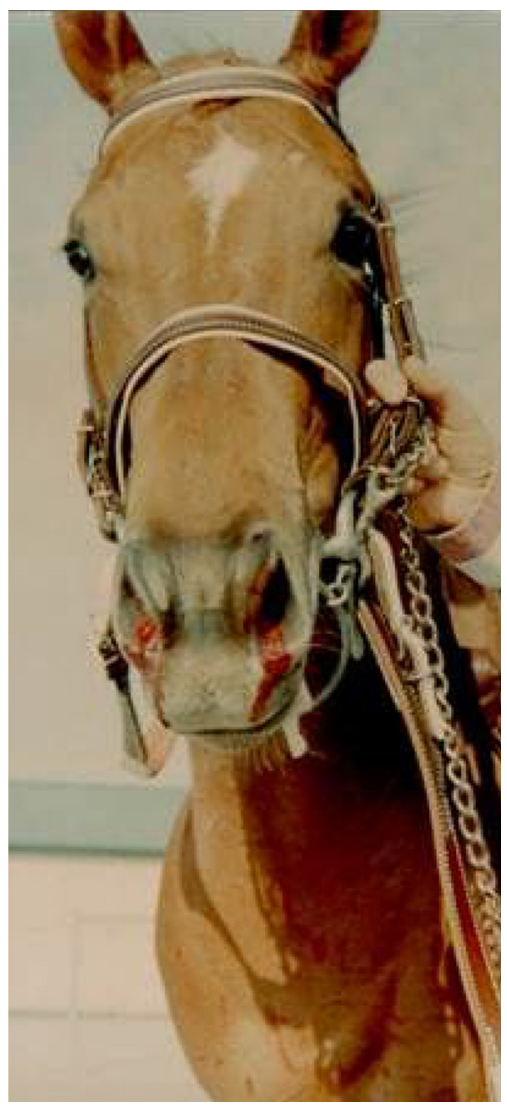

Figure I Epistaxis, bleeding from the nostrils, is the most visible form of exerciseinduced pulmonary hemorrhage.

Note: Photograph courtesy of Professor M Roger Fedde. in $1688,{ }^{20-22}$ and elite racehorses certainly have epistaxis in their ancestry. For instance, Bartlett's Childers was renamed from Bleeding Childers (b. 1716), and was the great Grandsire of the famous racehorse Eclipse (1764-1789), who never lost a race (Figure 2). Eclipse was so dominant that on October 18, 1770, in the King's Plate at Newmarket, his reputation so scared other owners that they withdrew their horses, and he simply walked the course unopposed! He went on to sire 334 winners. This case report demonstrates that horses with severe EIPH/epistaxis (Bleeding Childers not Eclipse) can perform at the highest levels, despite the epidemiological evidence that horses with the most severe EIPH do not perform as well as their less-affected counterparts. ${ }^{6,15,23-25}$ It is also true that there are genetic (as well as nongenetic) links to EIPH/epistaxis. ${ }^{26}$ However, it is pertinent that such research is extremely challenging, and therefore, conclusions must be tempered with this reality in mind. There is also a rather controversial retrospective study reporting greater career longevity for horses with EIPH! ${ }^{27}$

\section{Brief history of discoveries key to our understanding of EIPH}

Understanding the pathogenesis of EIPH has necessitated substantial progress in pulmonary and cardiovascular anatomy and physiology, and it is instructive to follow key elements of that progress. Whereas Galen (129 CE-c. 200/c.216) considered that most blood went through the lungs, he did hypothesize the existence of tiny pores through which blood passed from the right to the left ventricle. ${ }^{5}$ William Harvey (1578-1657) subsequently placed his "invisible porosities" within the lungs themselves and surmised that they were

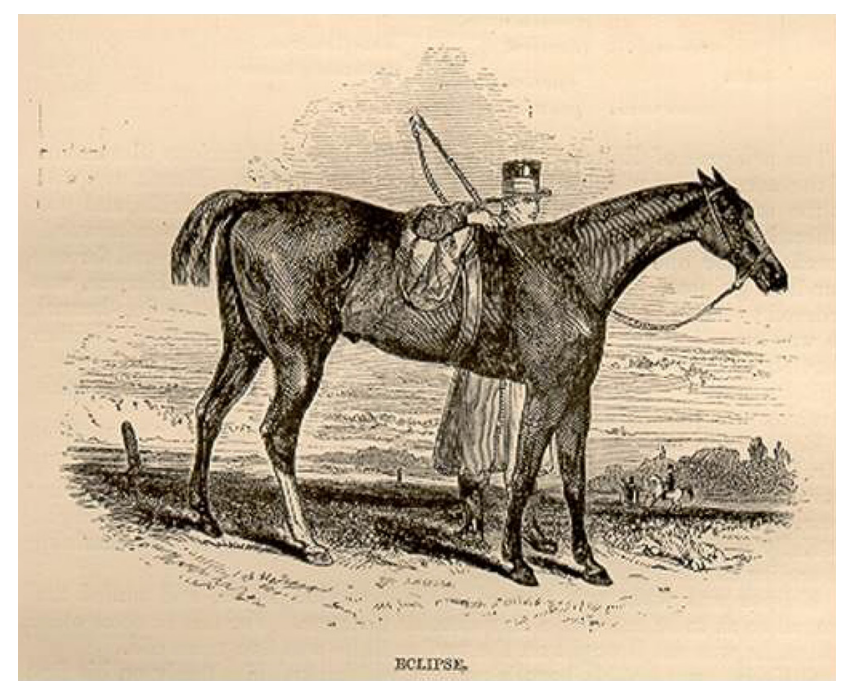

Figure 2 The acclaimed racehorse Eclipse, whose great Grandsire was Bleeding (Bartlett's) Childers (1764-1789).

Note: Reproduced from Youatt W. The Horse. London: Longmans, Green, and Co.; 1874. ${ }^{21}$ 

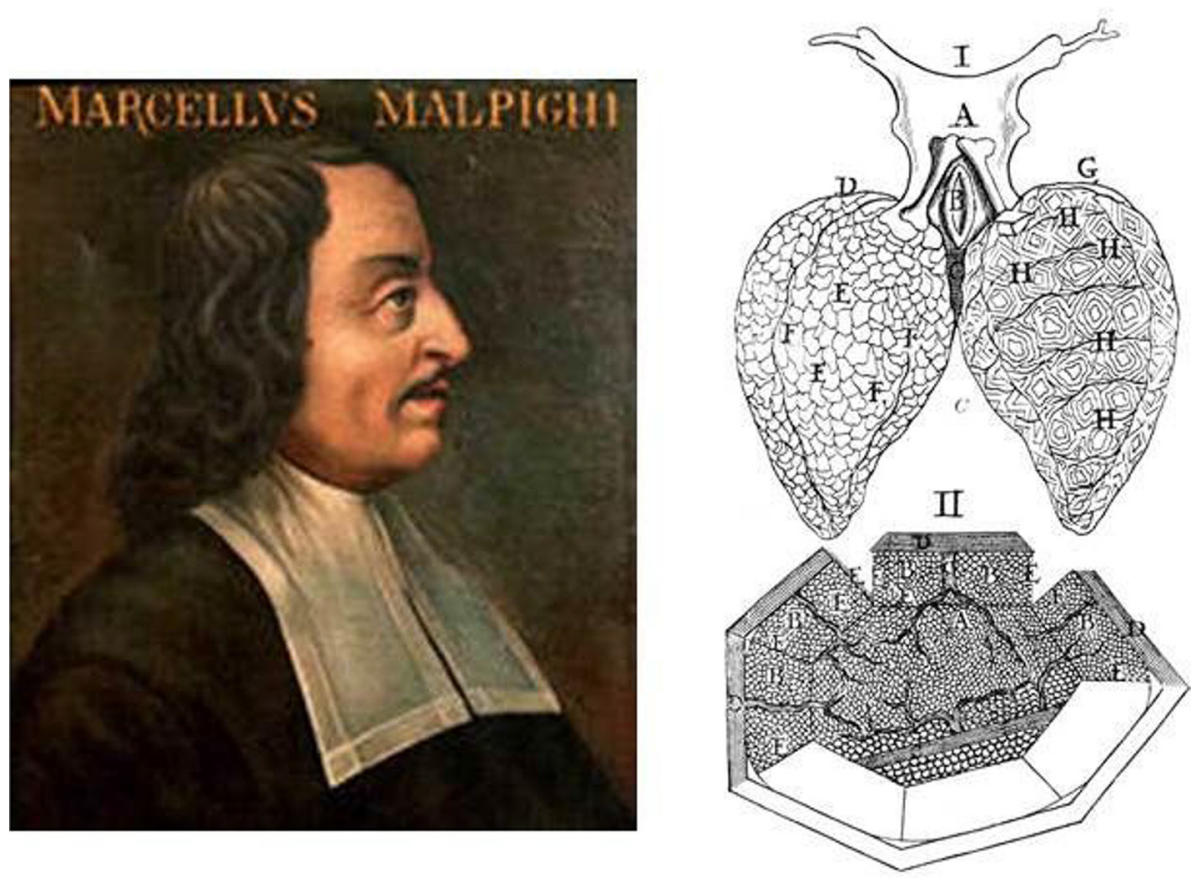

Figure 3 Left: Marcello Malpighi, professor of medicine and extraordinary anatomist and physiologist (I628-1694). Right: Malpighi's depiction of the pulmonary capillaries and alveoli. I: 2 lungs with the alveoli on the left and the capillaries on the right. II: pulmonary capillaries in the alveolus dissected open reveal the incredible density of capillaries that form the blood-gas barrier.

Note: Adapted from Malpighi M. De Pulmonibus [Lungs]. London: Philosophical Transactions of the Royal Society; I66I. Latin. ${ }^{29}$

actually small blood vessels.$^{28}$ However, Harvey and his contemporaries considered the lungs to comprise solid material as for the liver. It was only in the early 1660 s, with the use of hand lenses and very early compound microscopes, that Marcello Malpighi (1628-1694) simultaneously discovered the pulmonary capillaries and alveoli in the lungs of the living frog (Figure 3). ${ }^{29,30}$ Albert von Kölliker (1817-1905) in 1881 first described the Type I and II pneumocytes ${ }^{5}$ that we now know constitute the "thin" portion of the blood-gas barrier for gas exchange and synthesize pulmonary surfactant essential for reducing surface tension and setting the extraordinary compliance of the lung, respectively. But it was only with the development of the electron microscope and its application to the pulmonary capillaries that Frank Low (1911-1998) visualized the exquisitely fine structure of the blood-gas barrier. His electron micrographs identified its tripartite structure consisting of the capillary endothelium, the alveolar epithelium and the intervening basement membrane with an in toto thickness of $<0.5 \mu \mathrm{m}$ in 2 seminal papers published in 1952 and $1953 .{ }^{31,32}$ Because gases diffuse far more slowly through fluids than air $\left(>10^{-5}\right)$ and exercise, especially in highly aerobic mammals such as the horse and dog, demands extremely high rates of oxygen and carbon dioxide transport across the blood-gas barrier, there has been strong selective pressure to ensure its thinness. It is worth remembering that the capacity for the lung to exchange oxygen and carbon dioxide is dependent upon the ratio of its functional surface area formed by Type I cells, some $2,800 \mathrm{~m}^{2}$ in the racehorse, to the thickness of the blood-gas barrier $(\sim 0.5 \mu \mathrm{m})$. To grasp the true enormity of this ratio, if we increased the blood-gas barrier thickness to 1 inch (ie, $\times 56,000)$ and did the same to the surface area, its $144 \mathrm{~km}^{2}$ would more than cover the world's 5 smallest countries (San Marino, Tuvalu, Nauru, Monaco and Vatican City)!

Despite recognition of the thinness of the blood-gas barrier and the awareness that blood erupted into the alveolar space in diseases such as mitral stenosis which are characterized by high pulmonary vascular pressures, ${ }^{33,34}$ the source of the blood in EIPH was curiously attributed to the mucosa of the terminal bronchioles (ie, larger systemic circulation vessels). This situation persisted for 4 decades, and West considers 3 reasons for this blind spot in understanding how the pulmonary capillaries can rupture: $\left.{ }^{5} 1\right)$ Misunderstanding of Laplace's equation. Specifically, the capillary wall stress $(S)$ is calculated as $S=(P \times r) / t$, where $P$ is transmural pressure, $r$ is radius and $t$ is wall thickness. As the strength of the blood-gas barrier comes from the $0.05 \mu \mathrm{m}$ (ie, $50 \mathrm{~nm}$ ) Type IV collagen of the basement membrane, $S$ becomes very high despite $r$ being only 3-5 $\mu \mathrm{m}$. 2) Lack of capillary rupture in other tissues. In stark contrast to the gas surrounding the pulmonary capillaries, their counterparts in muscle and other tissues are supported by the adjacent tissue matrix and also collagen struts ${ }^{35,36}$ such 
that their transmural pressures remain very low. They are thus not subject to catastrophic failure. 3) Lack of appreciation of elevated pulmonary artery pressures during exercise. Because the human pulmonary artery mean pressure at rest is low in comparison to the systemic (ie, $\sim 15$ versus $\sim 93 \mathrm{mmHg}$ ), and it was not considered to be much elevated during exercise, high capillary transmural pressures were not suspected in healthy individuals. However, in 1986, Wagner et al measured elevated mean pulmonary artery and wedge pressures (estimate of venous and capillary pressures) in healthy humans during heavy but submaximal cycle ergometer exercise. ${ }^{37}$ Pulmonary artery pressure increased from 15 to $37 \mathrm{mmHg}$ and wedge pressure from 14 to $21 \mathrm{mmHg}$ demonstrating that pulmonary capillary pressures can become elevated during exercise.

In 1981 , endoscopy revealed that $\sim 70 \%$ of horses postrace had significant blood in their airways, ${ }^{38}$ and subsequently hemosiderin-laden macrophages were recovered in tracheal washings from Thoroughbred horses in training. ${ }^{39}$ It is now recognized that the vast majority, if not all, performance horses experience EIPH (Figure 4), ${ }^{2,6}$ but fatalities attributed to EIPH are uncommon (Figure 5).

Thoroughbred horses have been bred for speed which has selected preferentially for a heart that can be up to $2 \%$ of their body mass compared with $0.5-1 \%$ for other mammalian species. ${ }^{40}$ This has resulted in horses capable of generating cardiac outputs in excess of $400 \mathrm{~L} / \mathrm{min}$ and achieving maximal oxygen uptakes well over $80 \mathrm{~L} / \mathrm{min}$ - the highest measured to date in any species. To achieve these prodigious blood and oxygen

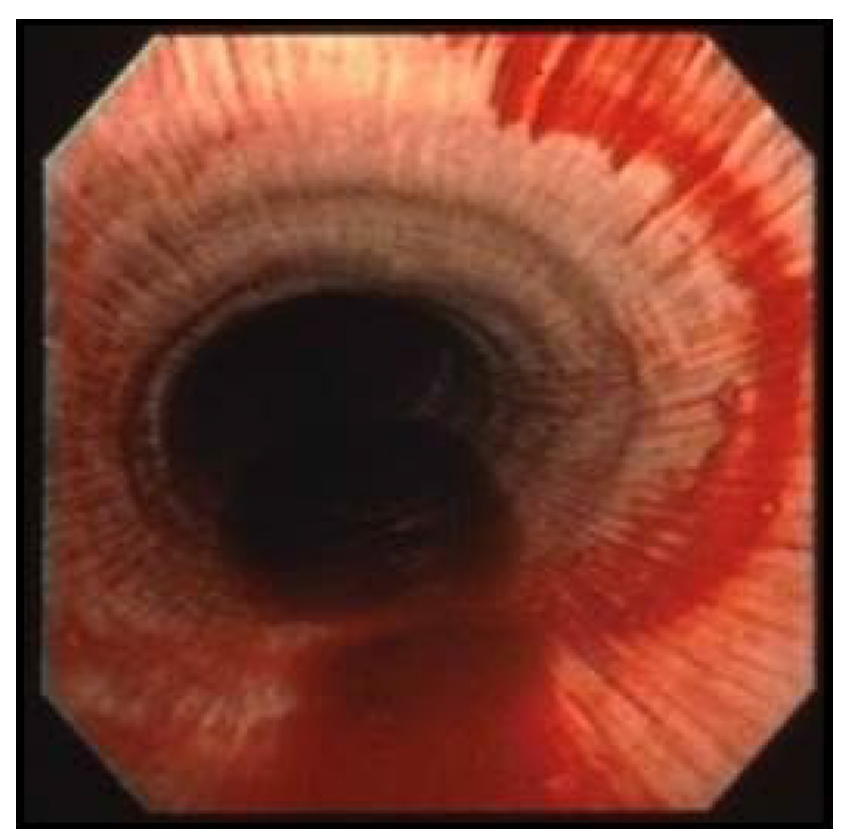

Figure 4 Blood in the trachea of a racehorse after maximal exercise as revealed by endoscopy.

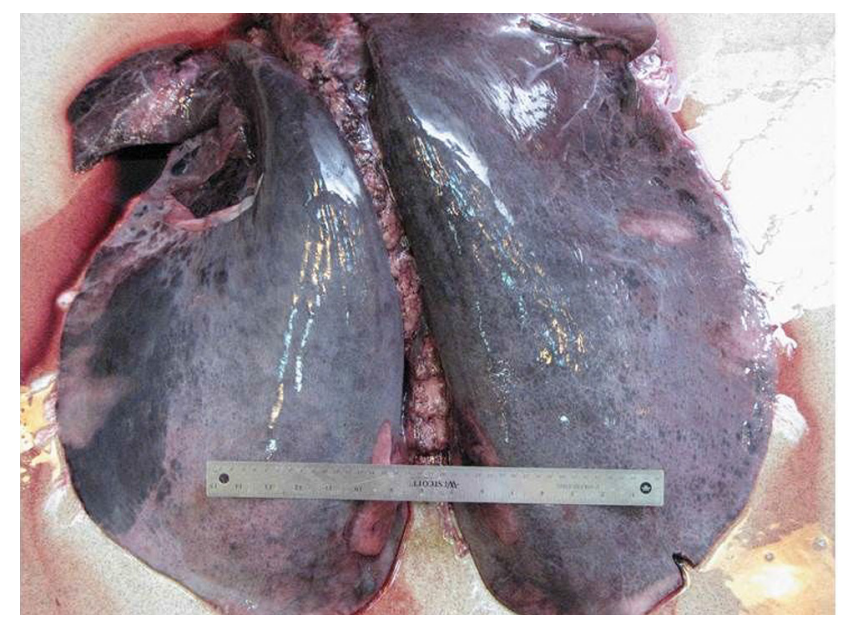

Figure 5 Lungs excised from a horse with a rare fatal instance of exercise-induced pulmonary hemorrhage.

Note: Photograph courtesy of Dr Kurt J Williams.

fluxes, left ventricular filling pressures must be extraordinarily high and elevate pulmonary venous and capillary intraluminal pressures. In 1992, the first peer-reviewed paper was published demonstrating prodigiously high pulmonary artery pressures in horses during high-intensity treadmill running. ${ }^{41-44}$ These groundbreaking studies demonstrated that, simultaneously with mean systemic arterial pressures of $240 \mathrm{mmHg}$, mean pulmonary artery pressures reached $\sim 120 \mathrm{mmHg}$, and directly measured left atrial pressure peaked at $70 \mathrm{mmHg}$. From such measurements, capillary intraluminal pressures in the region of $100 \mathrm{mmHg}$ have been estimated (Figure 6).

\section{The "other" side of the blood-gas barrier}

Notwithstanding the extraordinary dimensions of racehorse lung surface area, the physical constraints of the chest wall have resulted in a structure that is underbuilt in comparison with the heart. In addition, the necessity for long extrathoracic airways (increasing dead space and airway(s) resistance) and the presence of collapsible nasal passageways provide additional impediments to pulmonary function. ${ }^{40,45,46}$ For an elite horse achieving $90 \mathrm{~L} / \mathrm{min}$ oxygen uptake during the gallop with a $3 \mathrm{~L}$ dead space and a respiratory frequency of 130 breaths per minute, controlling its arterial $\mathrm{CO}_{2}$ pressure at resting values of $40 \mathrm{mmHg}$ would necessitate $\sim 2,400 \mathrm{~L} /$ min total ventilation. Whereas humans typically hyperventilate driving arterial $\mathrm{CO}_{2}$ pressures down to $30 \mathrm{mmHg}$ or so to help constrain the exercise-induced acidemia, the horse actually hypoventilates and allows its arterial $\mathrm{CO}_{2}$ to rise to $\sim 60 \mathrm{mmHg} .{ }^{42}$ Although this situation exacerbates the arterial hypoxemia - the primary cause being the very short red blood cell $(\mathrm{RBC})$ transit times in the pulmonary capillaries - it lowers the ventilatory demands of the exercise to an 


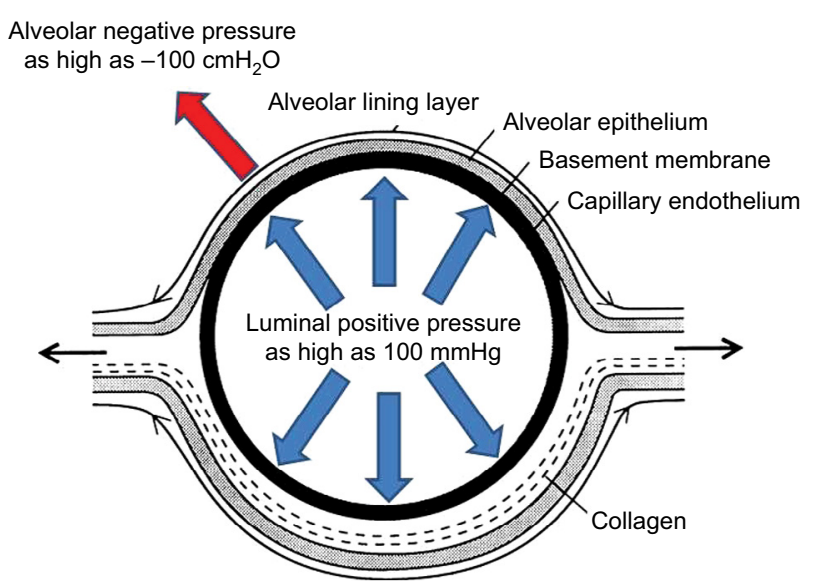

Figure 6 Schematic depicting cross-section of a pulmonary capillary.

Notes: Alveolar negative and capillary luminal positive pressures summate across the perilously thin $(0.5 \mu \mathrm{m}$ total thickness, $50 \mathrm{~nm}$ basement membrane thickness) blood-gas barrier. Pressures shown are for maximal exercise in the horse.

achievable $\sim 1,700 \mathrm{~L} / \mathrm{min}$. Even so, attaining the required peak flow rates approaching $120 \mathrm{~L} / \mathrm{min}$ necessitates extremely low airway, and especially, alveolar negative pressures that may exceed $-100 \mathrm{cmH}_{2} \mathrm{O}$. It is this negative pressure that summates with the positive intraluminal pressure across the thin blood-gas barrier rupturing it and causing EIPH.

The most compelling evidence that the pulmonary capillaries constitute the unequivocal site of EIPH includes the following:

1. Only microspheres (10 and $15 \mu \mathrm{m}$ diameter, differentially colored) injected into the jugular vein appear in the airways during a bout of EIPH. Those injected into the left atrium do not. ${ }^{43}$

2. There is irrefutable electron micrographic evidence for catastrophic pulmonary capillary rupture and RBCs escaping into the alveolar space in equids following heavy-/severe-intensity running (Figure 7). 5,16,43

3. Although there are exceptions, as discussed in the "EIPH causes and mechanisms" section, the majority of conditions that reduce the transmural pressure across the pulmonary capillary (eg, Lasix, nasal strip, correction of laryngeal hemiplegia) reduce EIPH, whereas elevation of capillary transmural pressures increases EIPH (eg, L-nitroarginine methyl ester [L-NAME]-induced pulmonary hypertension, inclined running, laryngeal hemiplegia/experimental increase of upper airway resistance)., ${ }^{2,5}$

Consequently, the most effective approaches to reducing EIPH have focused on lowering either pulmonary capillary intraluminal pressures (furosemide/Lasix) or alveolar negative pressures (nasal strip, long-term management of airway health) as discussed in the "Prevention and treatment of EIPH" section.

\section{Diagnosis and prevalence Epistaxis}

Visible epistaxis, as seen in Figure 1, was the original method of diagnosing EIPH, and although considered to be a serious problem, its relatively rare occurrence $(0.25-13 \%$ of all sprinting horses $)^{47-49}$ mitigated concern. A comprehensive analysis of 250,000 race starts published in 2001 reported the incidence of overt epistaxis to be only $0.15 \%{ }^{50}$ That investigation and subsequent work (some using endoscopy) noted that epistaxis/EIPH was most prevalent for the following:

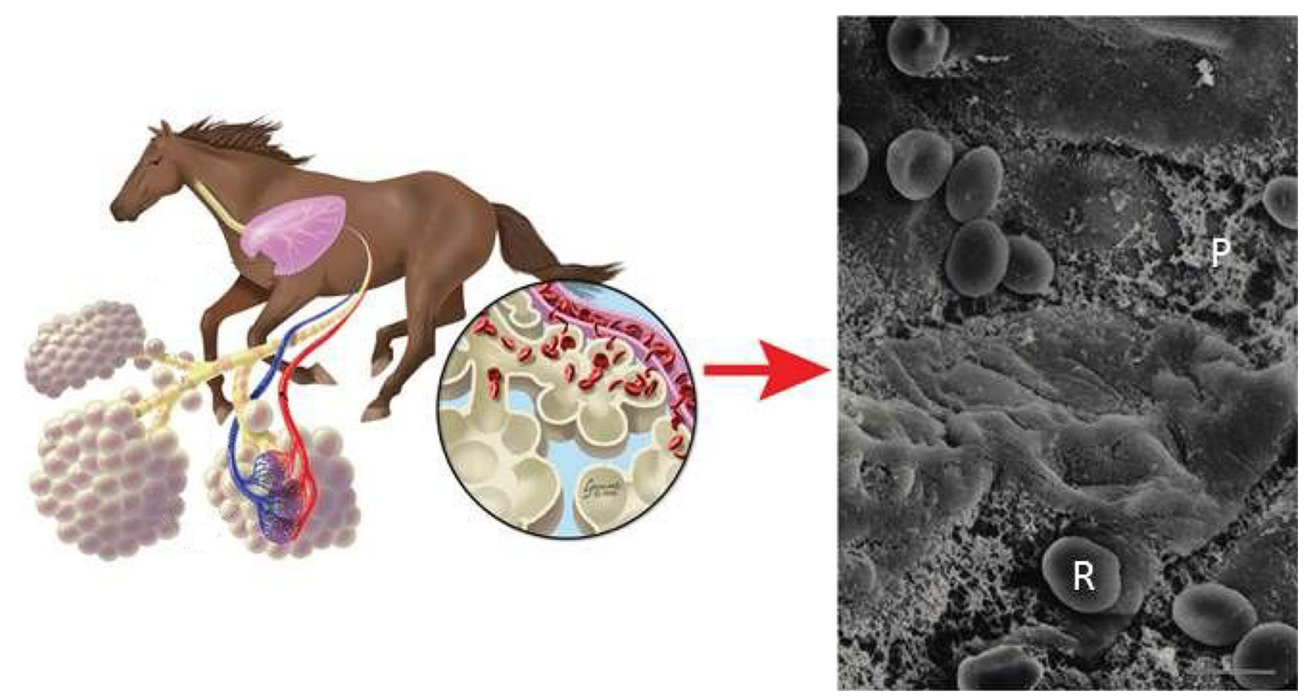

Figure 7 Left: Schematic showing exercise-induced pulmonary hemorrhage in the horse. Right: Scanning electron micrograph of the cranial lobe of an exercised pony reveals red blood cells $(R)$ and proteinaceous material $(P)$ in the alveoli. Bar $=5 \mu \mathrm{m}$.

Notes: Left diagram courtesy of Flair, LLC by Brad Gilleland. Right figure adapted with permission from Erickson HH, McAvoy JL, Westfall JA. Exercise-induced changes in the lung of Shetland ponies: ultrastructure and morphometry. J Submicrosc Cytol Pathol. 1997;29(1):65-72. ${ }^{16}$ 
1. shorter higher intensity races (greater pulmonary intravascular [positive] and extravascular [negative] pressures),

2. steeplechase compared with flat races (greater tidal volumes and respiratory/impact forces), ${ }^{50-52}$

3 . older in preference to younger ( $\sim 2$-year olds) horses (more race starts), ${ }^{53}$

4. males rather than females (latter may retire earlier to breed), ${ }^{6}$ and

5. cool ambient temperatures. ${ }^{53,54}$

\section{Bronchoalveolar lavage (BAL)}

BAL when feasible is considered to provide the most sensitive determination of EIPH severity compared with tracheal lavage or endoscopy. ${ }^{55-59}$ Performed ideally $30 \mathrm{~min}$ post-race, the procedure consists of inserting either an endoscope or preferably a long, soft flexible tube into the naris which invariably wedges in a subsegmental bronchus subserving the dorsocaudal lobe. ${ }^{45,60}$ Then, $300 \mathrm{~mL}$ of phosphate-buffered saline ( $\mathrm{pH} 7.4$, $300 \mathrm{mosm}$ ) is infused in $50 \mathrm{~mL}$ aliquots, and after 2 breaths, aspirated. Fluid recovery of $\geq 55 \%$ is acceptable, and that fluid is then analyzed for the cell populations of interest. BAL facilitates an accurate analysis of the cytological population in the terminal airways and alveolar spaces. Investigations using BAL indicate that hemorrhage occurs in almost all horses in racing or training, ${ }^{2,60,61}$ and BAL cytological findings cohere closely with clinical disease, pulmonary histopathology and endoscopic evidence of EIPH. ${ }^{57-60}$ Concerns regarding BAL most often include the need for rapid access to the horse postrace, the need for sedation (eg, 10-20 $\mu \mathrm{g} / \mathrm{kg}$ intravenous detomidine), whether the entire lung volume affected by EIPH is sampled and the potential for heterogeneity of EIPH between lungs. ${ }^{62}$ To date, many of the incisive investigations into the impact of furosemide, the nasal strip, immunomodulation and other therapeutic strategies on EIPH have successfully utilized BAL. 1,3,45,55,59-61,63,65-73 By comparison, endoscopy (vide infra) evaluation is extremely crude (Figure 4$)^{75}$ and also depends on transduction of blood into the trachea which may be a time- and posture-dependent process.

\section{Endoscopy}

Use of a rigid endoscope enabled Cook in 1974 to recognize that the lungs, rather than extrathoracic airways or other putative sites, were the source of hemorrhage. ${ }^{47}$ Endoscopy increased the detection of post-race EIPH to up to over $60 \%$ in Standardbreds, ${ }^{76,77}$ Quarter Horses ${ }^{78}$ and Thoroughbreds. ${ }^{49,79-82}$ Repeated examination of individual horses raised the detected incidence of EIPH to $~ 95 \%{ }^{78,80,81}$

\section{Tracheal lavage}

Whereas tracheal lavage can detect EIPH from the presence of hemosiderophages in the fluid aspirated, defining the time course of the hemorrhage is challenging. Moreover, the relationship between tracheal wash cytology and lung histopathology is weak..$^{39,83,84}$ It is also concerning that the cell population in the tracheal fluid is markedly different from that in the lower respiratory tract..$^{83,84}$

\section{Radiography}

EIPH is only vaguely discernible by radiography as an increase in interstitial density in the dorsocaudal lobe of the $\operatorname{lung}^{85-88}$ and is therefore of limited value. Potentially in horses with severe, repeated EIPH episodes, radiography may be of use in documenting EIPH progression.

\section{Echocardiography}

Echocardiography may reveal a higher incidence of spontaneous contrast at rest in horses with a history of EIPH, but it is not quantitative. ${ }^{89-91}$

\section{Nuclear scintigraphy}

Small amounts of hemorrhage may potentially be detected with scintigraphy, but this is contingent upon the level of lung background radioactivity ${ }^{92}$ and results have generally been disappointing. 2,85

There is no doubt that scientific progress into understanding EIPH mechanisms and treatment is dependent on evaluating bleeding severity acutely, as with BAL. But it is also true that assessment of the long-term impact of successive EIPH episodes will inform putative therapeutic strategies including race-race interval, immunomodulation, pre-race interventions, training regimens and possibly diet and breeding programs. Thus, development of an effective technique to assess pulmonary venous remodeling ${ }^{93,94}$ and the mechanical sequelae to repeated EIPH episodes in vivo would be extremely valuable.

\section{EIPH causes and mechanisms}

A variety of causes and pathophysiologic mechanisms have been postulated for EIPH. The experimental evidence indicates that a given instance of EIPH may be caused or exacerbated by multiple factors acting in concert. ${ }^{2}$ These can be grouped broadly into 3 primary categories that involve intravascular pressures (capillary, positive), extravascular pressures (alveolar, negative) and properties of the blood-gas barrier (strength/ fragility) and lung parenchyma (reduced compliance/fibrosis). 


\section{High pulmonary capillary intravascular pressures}

Pulmonary artery pressure is set by the product of cardiac output and pulmonary vascular resistance. As mentioned earlier, the immense heart size of the racehorse results in a huge stroke volume which, combined with maximal heart rates of $\sim 240$ beats per minute, results in extraordinary pulmonary blood flows. The pulmonary vascular resistance will in turn be set by the cross-sectional area of the resistance vessels and hemorheological properties (ie, apparent viscosity) of the blood at a hematocrit of $\geq 65 \%$. Thus, the driving pressure in the pulmonary artery will increase to achieve the required flow irrespective of downstream venous pressures, and those pressures are elevated as the left ventricle becomes stiff (rate of relaxation is inadequate) requiring an elevated filling (left atrial) pressure. The pulmonary capillaries are thus caught between extremely high pulmonary artery pressures of $\sim 120 \mathrm{mmHg}$ and left atrial pressures that may rise to $\geq 70 \mathrm{mmHg}$ such that mean pulmonary capillary pressures of $100 \mathrm{mmHg}$ are feasible (Figure 6). Two additional factors have been considered to also play a role in the elevated pulmonary vascular pressures: the resistance provided by the comparatively small cross-sectional area of the atrioventricular valves and regurgitation through these valves during ventricular systole when left ventricular pressures may be $\geq 240 \mathrm{mmHg}$. ${ }^{40}$

Pulmonary blood flow in the equine lung is neither homogeneous nor distributed according to gravitational control. ${ }^{95}$ Rather, arteriolar vasomotor control favors a preferential vasodilation toward the dorsal aspect of the lung such that blood flow increases from ventral-dorsal regions (ie, opposite to that expected from gravitational effects) and specifically is highest toward the dorsocaudal region that is most impacted by EIPH. ${ }^{95-99}$

\section{Very high negative alveolar pressures}

Generating peak inspiratory flow rates of $\sim 120 \mathrm{~L} / \mathrm{s}$ against the resistance provided by the horse's long extrathoracic airways demands a steep pressure gradient and hence extremely negative alveolar pressures (Figure 6). ${ }^{45,100,101}$ Anything that reduces airway(s) cross-sectional area will either compromise airflow or require an elevated driving pressure to maintain the same flow. Because the bulk of the pulmonary resistance especially during inspiration is located in the large extrathoracic airways ${ }^{88,101}$ upper airway obstruction, as caused by sucking in the soft tissue overlying the nasal passageways just rostral to the nasoincisive notch, profoundly increases airway resistance. ${ }^{1,70,100,102,103}$ This phenomenon requires even more negative alveolar pressures and is expected to exacerbate capillary rupture. Laryngeal hemiplegia, often identified as a pronounced roaring on inhalation, is also a cause of elevated large airway resistance and hence more negative alveolar pressures. ${ }^{104,105}$ Because the small airways constitute relatively little to total airways resistance owing to their far greater total (combined) cross-sectional area, their potential to increase total inspiratory resistance is far less. However, given its high prevalence, ${ }^{106}$ extensive small airways disease has certainly been considered as a potential contributing factor to EIPH, and even airway disease that is subclinical at rest may become important during maximal exercise. It is pertinent that there is a demonstrable association between lower airway disease and $\mathrm{EIPH}^{107,108}$ and also that experimentally induced inflammation, consequent to instillation of dilute acetic acid into the distal bronchi, increases EIPH severity. ${ }^{109}$ Instillation of blood into the airways also causes a transient airway inflammation that resolves within 2 weeks, ${ }^{110}$ but the fibrotic lesions characteristic of the lungs of horses with a prolonged history of EIPH may well require hemosiderin within the interstitial space. ${ }^{111}$ That not all horses with EIPH have any evidence of lower airway inflammation supports that this condition may exacerbate EIPH, but it by no means is a primary cause. ${ }^{6}$

\section{Chronic lung damage}

EIPH is associated with edema and blood in the alveolar space, small airways and interstitium. This produces airway irritation and inflammation, and with repeated strenuous exercise in either training or actual competition, the hemorrhage results in fibrosis/scarring, a weakened blood-gas barrier and sustained inflammation. The blood within the alveoli may adversely affect lung health and exercise capacity by interfering with gas exchange. Because chronic scarification changes the compliance properties of the lung and progresses as a "front" between 2 regions, diseased and healthy, there may be substantial shearing forces at the junction of these regions which increases capillary rupture and EIPH particularly upon forceful inhalation. There will also be the progression of veno-occlusive disease with repeated bouts of EIPH that further elevates pulmonary venous and capillary pressures. Specifically, repeated instances of hemosiderin accumulation, and possibly their inflammatory consequences, induce veno-occlusive remodeling of smalldiameter $(100-200 \mu \mathrm{m})$ pulmonary veins primarily in the dorsocaudal region and fibrosis of the alveolar interstitium, bronchovascular bundle, septa and pleura. ${ }^{19,93,94,97-99,112}$ Both of these factors help explain how chronic EIPH worsens with repeated exercise and consequently increased age. An 
important question is how much exercise and EIPH-induced damage is required to induce these changes. Certainly, it appears to be $>2$ weeks of intensive exercise training at least for the expected alterations in mRNA and protein expression which may be necessary precursors. ${ }^{6,94}$

\section{Mechanical stresses of respiration and locomotion}

Lung tissue is damaged by thoracic impact, and Schroter et al have suggested that the locomotory impact of the forelimbs produces a localized impulsive load on the chest wall sending pressure waves through the lung parenchyma. ${ }^{52,53,113}$ These waves increase in magnitude, and therefore destructive potential, as the mass of affected tissue decreases toward the dorsocaudal lobe - the primary site of capillary rupture. For a $500 \mathrm{~kg}$ horse at the gallop, it is estimated that impulsive forces in excess of $100 \mathrm{kPa}$ of $10 \mathrm{~ms}$ duration would be applied to the horses' chest by each scapula which is expected to produce edema and hemorrhage. This elegant theory helps explain why horses that jump (steeplechase, eventing) generally experience greater EIPH than flat racers. ${ }^{2}$

\section{Prevention and treatment of EIPH}

Given the complex etiology of EIPH, it is not surprising that this condition has not been eradicated or that a unified treatment strategy has not been identified. Therapeutic countermeasures at best reduce but do not prevent EIPH and are aimed at either constraining the severity of EIPH or reducing the pernicious sequelae including inflammation and infection as well as possibly fibrosis and venous remodeling. Moreover, the issue is complicated by fact that the weight loss induced by the diuretic furosemide is a substantial performance enhancer as absolute $\dot{V} \mathrm{O}_{2} \max$ is unaltered and the $\sim 20 \mathrm{~kg}$ weight loss therefore increases mass-specific $\dot{V} \mathrm{O}_{2} \max .{ }^{114-117}$ The failure of investigations to quantify EIPH by BAL has also led to confusion, and in some instances, misdirection (eg, using endoscopy). ${ }^{75}$ Given the pressing and continued demand for effective prophylaxis and/or treatment to reduce EIPH, an extensive variety of pharmacotherapeutic and management interventions have been developed. However, under scientific scrutiny, few of these have demonstrated efficacy in treating EIPH..$^{1-3,6,118-120}$ Treatments proposed for EIPH are generally directed at or more than 1 of the putative causal mechanisms for EIPH considered earlier and include ${ }^{2,6}$ furosemide and other diuretics, dehydration, antihypertensive agents or pulmonary vasodilators that dilate the pulmonary vasculature (eg, nitric oxide [NO] inhalation, endothelin inhibition), drugs to decrease blood viscosity (eg, pentoxifylline), inhibition of platelet aggregation, transhexamic acid to inhibit fibrinolysis, nasal dilator strips to reduce the resistance and maintain full patency of the nasal passages, bronchodilators, surgical correction of laryngeal hemiplegia to decrease upper airway resistance, anti-inflammatory drugs/ strategies to reduce lower airway inflammation, hesperidincitrus bioflavinoids to reduce capillary fragility, aminocaproic acid and herbal remedies. ${ }^{2,6,68,118-120}$ Given that EIPH risk does not relate to any discernible combination of horse's age, race distance/speed, air quality or track hardness, ${ }^{53}$ the following discourse focuses on interventions and treatments mentioned that either offer significant potential to treat EIPH and/or for which novel information is available.

\section{Furosemide (Lasix, Salix, Frusemide)}

Where permitted in North America, South America, Saudi Arabia and the Philippines, ${ }^{2,119}$ furosemide is the most commonly used race-day EIPH treatment. ${ }^{121-127}$ Typically administered 4 hours prior to racing, furosemide induces a vigorous diuresis and reduces EIPH (as assessed by BAL; Figure 8$)^{68,69,127,128}$ by constraining the exercise-induced elevation of right atrial, pulmonary arterial, pulmonary wedge and pulmonary capillary pressures. ${ }^{42,68,69,129-132}$ There may also be a redistribution of pulmonary blood flow such that flow decreases to the "at-risk" dorsal lung regions. ${ }^{133}$ Specifically,

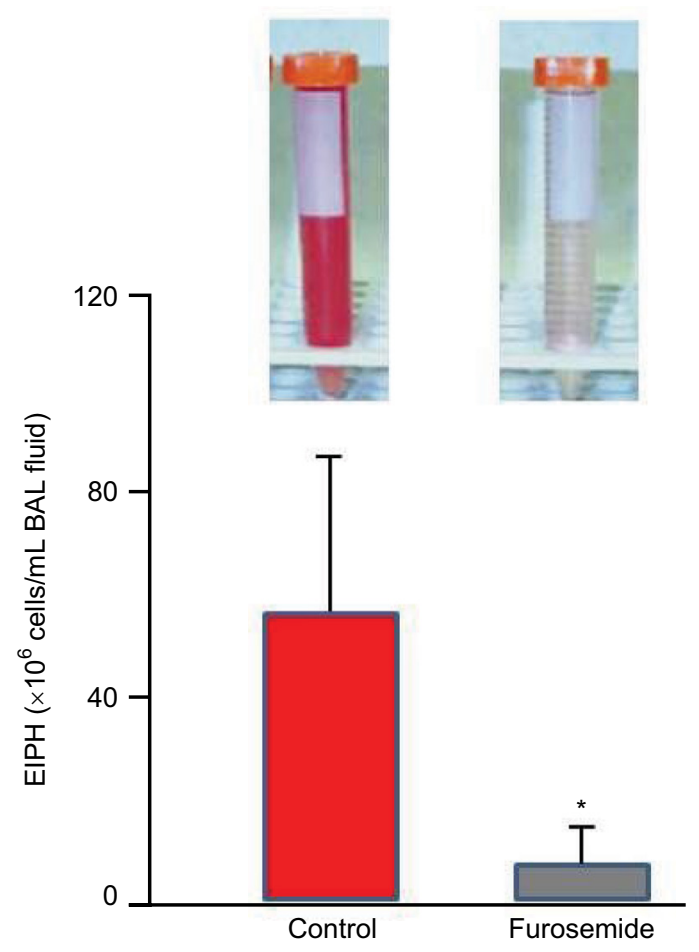

Figure 8 The diuretic furosemide significantly $(*)$ reduced exercise-induced pulmonary hemorrhage during high-intensity exercise as measured by bronchoalveolar lavage. Notes: Vials upper left and right indicate, respectively, the appearance of BAL fluid from Control and Furosemide conditions. This effect is believed to be driven by the reduction in pulmonary blood flow and thus capillary intraluminal pressures. Adapted from Kindig CA, McDonough P, Fenton G, Poole DC, Erickson HH. Efficacy of nasal strip and furosemide in mitigating exercise-induced pulmonary hemorrhage in Thoroughbred horses.J Appl Physiol. 2001;91(3):1396-1400.68

Abbreviations: EIPH, exercise-induced pulmonary hemorrhage; BAL, bronchoalveolar lavage. 
furosemide administered intravenously decreased EIPH by $80-90 \%$ in Thoroughbred horses run to $\sim 95 \%$ ( $1 \mathrm{mg} / \mathrm{kg}$ furosemide ) and $120 \%(0.5 \mathrm{mg} / \mathrm{kg}$ furosemide $)$ of their $\dot{V} \mathrm{O}_{2} \max$ on the high-speed treadmill. ${ }^{68,69}$ Moreover, a systematic review and meta-analysis of 11 studies documented furosemide's efficacy for reducing EIPH in over 5,000 Thoroughbred and Standardbred racehorses. ${ }^{24}$ There has been much consideration of furosemide's vasodilatory effect on the smooth muscle of the pulmonary vasculature and bronchi. However, its pharmacokinetics is such that mean plasma levels will be in the very low $\mathrm{ng} / \mathrm{mL}$ range 4 hours after administration of the regulation dose, ${ }^{134}$ and as such, these direct effects are highly unlikely.

\section{Nasal dilators}

Although external nasal dilator strips are of questionable efficacy for humans during exercise, at least where oral breathing is unobstructed, during exercise, horses are obligate nasal breathers. Accordingly, nasal resistance, and changes thereof, is of substantially greater importance to inspiratory mechanics and airflow in horses than humans. During forceful inhalations when galloping, partial collapse of the unsupported nasal passages occurs, and this increases airways resistance. Use of the FLAIR ${ }^{\mathrm{TM}}$ nasal strip to stabilize the nasal wall and prevent the partial airway collapse reduces intrapleural and alveolar pressure swings that contribute to capillary transmural pressures, ${ }^{100,103,135}$ thereby reducing EIPH by up to $50 \%$ as

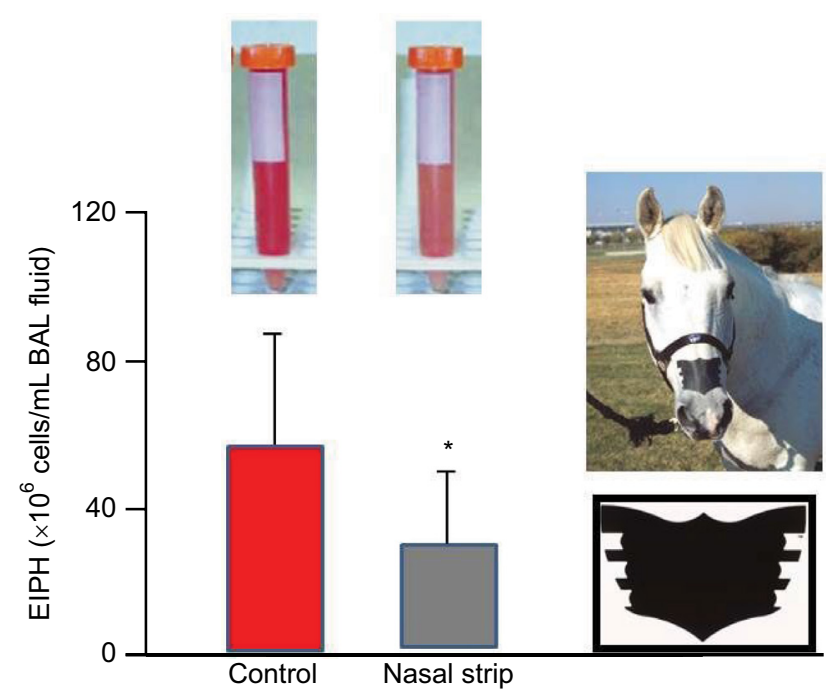

Figure 9 The nasal strip pictured at right significantly $(* P<0.05)$ reduced exerciseinduced pulmonary hemorrhage during high-intensity exercise as measured by bronchoalveolar lavage.

Notes: Vials upper left and right indicate, respectively, the appearance of BAL fluid from Control and Nasal strip conditions. This effect is caused by the less negative alveolar pressures and thus reduced capillary transmural pressures. Adapted from Kindig CA, McDonough P, Fenton G, Poole DC, Erickson HH. Efficacy of nasal strip and furosemide in mitigating exercise-induced pulmonary hemorrhage in Thoroughbred horses. J Appl Physiol. 2001;91(3):1396-1400.68

Abbreviations: EIPH, exercise-induced pulmonary hemorrhage; BAL, bronchoalveolar lavage. assessed by BAL (Figure 9). ${ }^{45,68,69,71}$ Moreover, those studies demonstrated that EIPH was reduced the most in those horses that were the heaviest bleeders on the control (no nasal strip) runs. Interestingly, during submaximal exercise, the nasal strip decreased $\dot{V} \mathrm{O}_{2}$, consistent with the horse performing less respiratory muscle work. As humans can redistribute their cardiac output among locomotory and respiratory muscles during maximal exercise, ${ }^{136}$ this raises the intriguing possibility that the nasal strip may enhance exercise performance if the blood flow (and $\mathrm{O}_{2}$ ) "spared" by the respiratory muscles was redistributed to the locomotory muscles. McDonough et $\mathrm{al}^{71}$ demonstrated that, in the presence of a substantial EIPH reduction, performance was enhanced by wearing the nasal strip.

Support for nasal strips benefitting racehorses on the track has emerged from studies of 400 horses at the Calder Race Course in Florida across the 1999-2000 Thoroughbred season (Scollay M and Hernandez J, unpublished findings, 2000). Horses wearing the nasal strip achieved a 3.4\% higher win percentage than their non-strip-wearing counterparts. Moreover, the nasal strip reduced the between-race interval from 29 to 23 days $(p<0.05)$. Subsequently, 30 Thoroughbred racehorses at the Golden Gate Fields Racetrack in California, who were identified as having a history of severe EIPH, achieved a $65 \%$ decrease in BAL-assessed EIPH. ${ }^{72}$ These studies emphasize the importance of using BAL rather than endoscopy to quantify BAL. ${ }^{75}$

The FLAIR nasal strip has been broadly approved for use in flat- and harness-racing within North America; most notably, it was approved for California Chrome, the Triple Crown contender, at Belmont Park in 2014. The FLAIR strip has also been approved for use by all key non-racing regulatory bodies, including the Federation Equestrian International, the American Horse Shows Association, the National Reining Association, the United States Equestrian Team, the United States Polo Association, the National Barrel Horse Association, and the American Quarter Horse Association. In the international market, the FLAIR strip has been approved for racing in the following countries: Mexico, Brazil, Trinidad, Barbados, Jamaica, the Netherlands, United Arab Emirates, Qatar, India, Australia (Harness), New Zealand, Korea and Singapore.

Whereas insufficient investigations have been performed to date on the nasal strip to conduct a meta-analysis, as for furosemide, ${ }^{24}$ the reduction in EIPH measured by BAL is substantial and robust enough to demonstrate statistical significance even with relatively small numbers of horses in each instance. ${ }^{45,68,69,71,72}$

\section{Nitric oxide}

NO is a vascular smooth muscle-relaxing factor that is produced endogenously via the action of NO synthase (NOS) 
on 1-arginine within vascular endothelial cells, muscles (preferentially Type II, fast twitch) and nervous tissues. ${ }^{137,138}$ In addition, dietary nitrate can be reduced to nitrite by facultative bacteria in the mouth; upon resorption, circulating nitrate is further reduced, especially by deoxygenated hemoglobin to NO. ${ }^{139}$ Inhibition of NOS using the 1-arginine analog L-NAME increases pulmonary artery pressure and EIPH in maximally exercising horses ${ }^{140-142}$ suggesting a key role for NO in mediating endothelial function during exercise. Whereas nitroglycerin forms NO and is a potent vasodilator, neither intravenous nor oral dosing reduces exercise-induced hypertension in the exercising horse. ${ }^{143,144}$ The same is true for the phosphodiesterase inhibitor sildenafil. ${ }^{145}$ In contrast, whereas inhalation of $80 \mathrm{ppm} \mathrm{NO}$ reduces pulmonary artery pressure in horses during heavy-/ severe-intensity exercise, it simultaneously increases EIPH as assessed by BAL (Figure 10). ${ }^{14-148}$ This dissociation of pulmonary artery pressure and EIPH by NO inhalation has revealed that pulmonary hypertension may, in part, be the consequence of downstream arteriolar vasoconstriction that actually protects the fragile dorsocaudal capillaries from high blood flows and associated pressures. Although NO lowers pulmonary artery pressure, it prevents this protective effect, and EIPH is actually worsened. ${ }^{148}$ This conclusion, regarding the effect of high pulmonary artery pressures being protective

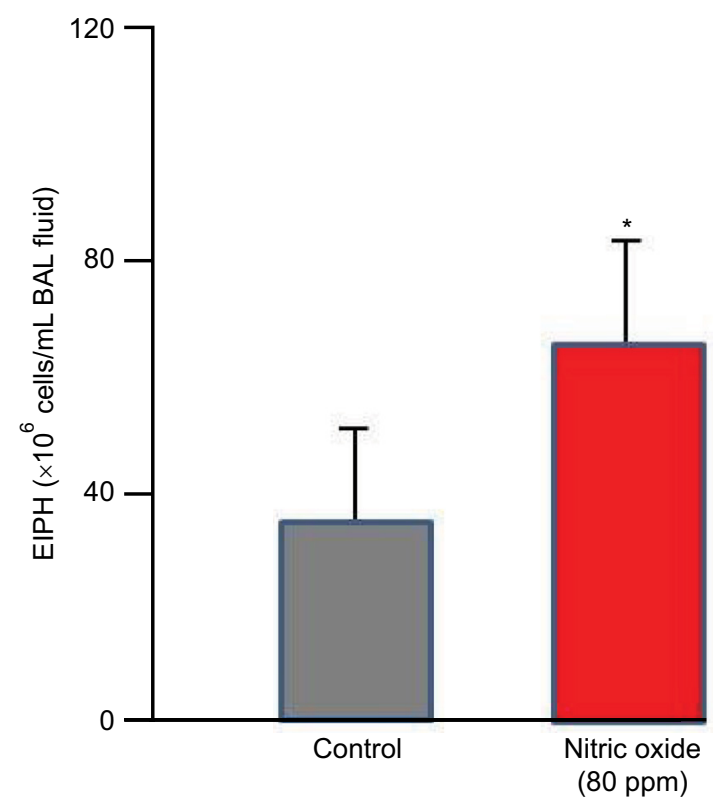

Figure 10 Inhaled nitric oxide $(80 \mathrm{ppm})$ lowered pulmonary vascular pressures substantially but significantly increased exercise-induced pulmonary hemorrhage as measured by bronchoalveolar lavage.

Notes: This demonstrates that some degree of pulmonary vasoconstriction is actually protecting the fragile pulmonary capillaries under control conditions. $* P<0.05$. Adapted from Kindig CA, McDonough P, Finley MR, et al. NO inhalation reduces pulmonary arterial pressure but not hemorrhage in maximally exercising horses. J Appl Physiol (1985). 200I;9I(6):2674-2678. ${ }^{148}$

Abbreviations: EIPH, exercise-induced pulmonary hemorrhage; BAL, bronchoalveolar lavage. in certain instances, is also supported by the elevated EIPH seen concomitant with reduced pulmonary artery pressures during inclined running. ${ }^{66}$

\section{Concentrated equine serum}

Because EIPH may be potentiated by inflammatory airway disease ${ }^{60,107,149}$ and EIPH severity is associated with increased IL-6 expression, ${ }^{150}$ strategies to reduce post-EIPH parenchymal tissue damage and subsequent scarring may be valuable. The concentrated equine serum (CES) Seramune ${ }^{\circledR}$ contains high levels of equine IgG and other immunoglobulins collected from draft horse donors. Following field studies that supported its potential therapeutic benefit to treat chronic EIPH sufferers and safety assessment, a dosage of $20 \mathrm{~mL}$ intratracheally and $10 \mathrm{~mL}$ intravenously was administered for 5 consecutive days with a booster dose weekly and 24-48 hours before heavy treadmill running. This treatment regimen was completed at different racetracks over a 5-year period and demonstrated a reduction in EIPH and mucus. This CES treatment reduced EIPH by $53 \%$ and white blood cells by $32 \%$ as assessed by BAL (Figure 11 ). ${ }^{120,151,152}$

\section{Omega-3 fatty acids}

Equine supplements often contain omega-3 fatty acids, and their capacity to impede the arachadonic acid cascade and thus airway inflammation has been hypothesized to decrease EIPH. Moreover, diets rich in docasahexaenoic acid (DHA) and eicosapentaenoic acid (EPA) may also constrain the

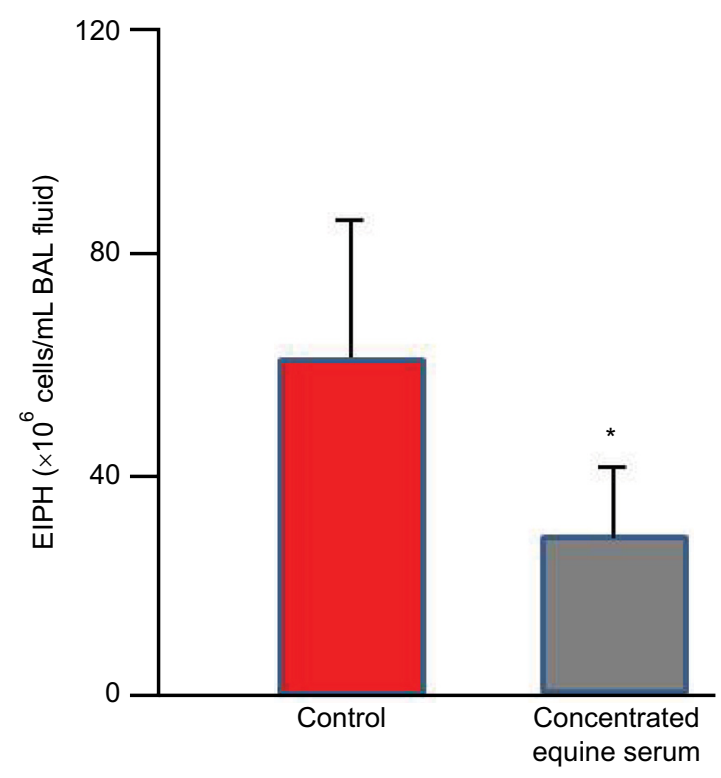

Figure II Concentrated equine serum decreased exercise-induced pulmonary hemorrhage during high-intensity exercise as measured by bronchoalveolar lavage. Notes: $* P<0.05$. Data from Epp et al. ${ }^{151}$

Abbreviations: EIPH, exercise-induced pulmonary hemorrhage; BAL, bronchoalveolar lavage. 
reduction in erythrocyte membrane fluidity during exercise and improve pulmonary hemodynamics reducing EIPH. ${ }^{153}$ This hypothesis was supported at Kansas State University where 10 Thoroughbred horses fed a DHA- and EPA-enriched diet for 83 and 145 days evidenced a decreased EIPH. ${ }^{67}$

\section{Herbal formulations}

A variety of herbal formulations that claim to "clear heat and edema from the lung, cool and nourish the blood, and move stagnated blood out of the airways" ${ }^{154,155}$ have been used to treat EIPH in horses. Some herbal formulations have also been designed to treat impaired coagulation and modify platelet function, both of which have been considered to contribute to EIPH. Within our laboratory, we find no evidence that Yunnan Paiyao and Single Immortal have efficacy for reducing EIPH in Thoroughbred racehorses. ${ }^{73}$

\section{Conjugated estrogens and antifibrinolytics}

Despite the absence of scientific evidence for increased fibrinolysis or impaired coagulation in horses with EIPH, ${ }^{156-158}$ use of conjugated estrogens and antifibrinolytics is widespread in the racing industry. Aminocaproic acid at 30 and $100 \mathrm{mg} / \mathrm{kg}$ (intravenous) doses in resting horses has an antifibrinolytic effect. ${ }^{159}$ Whereas both of these treatments, conjugated estrogens and aminocaproic acid, tended to decrease EIPH after severe-intensity treadmill, there was evidence for compromised running performance after aminocaproic acid. ${ }^{67,160,161}$ The potential of conjugated estrogens to decrease EIPH in some horses along with enhancing performance indicates the need for broader mechanistic investigation.

\section{Conclusion}

EIPH occurs in essentially all performance horses evaluated by BAL where, although rarely fatal, greater severity of bleeding has been associated with poor performance ${ }^{6}$ and may curtail racing longevity. EIPH becomes worse with advancing age most likely because older horses have more racing history and lifetime starts and therefore more structural and functional (mal)adaptations of the lungs. EIPH results from catastrophic mechanically induced rupture of the exquisitely thin blood-gas barrier that interposes between the pulmonary capillary blood and alveolar gas with the dorsocaudal regions of the lung most heavily impacted (Figure 7). Whereas the mechanistic bases for EIPH are complex, they summate as the effective capillary transmural pressure and the strength or integrity of the intervening blood-gas barrier (Figure 6). As such, anything that increases the positive capillary intravascular pressures or the negative alveolar pressures will exacerbate EIPH as will scarification or weakness of the barrier itself. Because the performance horse must achieve magnificently high cardiac outputs during maximal exercise, intravascular pressures reach levels normally associated with the systemic circulation (ie, $100 \mathrm{mmHg}$ ). ${ }^{45,46}$ Just $0.5 \mu \mathrm{m}$ away, the alveolar pressure must be extremely negative to draw air into the lungs at peak flow rates of $\geq 120 \mathrm{~L} / \mathrm{s}$ against an airways resistance that is accentuated by long extrathoracic airways, partial collapse of the nasal passages and possibly inflammatory compromise of small airway patency. In horses, pulmonary capillary (and presumably capillary transmural) pressures $>\sim 90 \mathrm{mmHg}$ in vitro ${ }^{48}$ and in vivo ${ }^{50}$ rupture the blood-gas barrier which heals rapidly after the pulmonary capillary hypertension is relieved. ${ }^{162}$ However, parenchymal damage and associated inflammatory processes combined with RBCs remaining in the lung interstitium drive structural and mechanical changes that not only compromise barrier strength and integrity but also elevate pulmonary vascular pressures during subsequent exercise bouts (ie, veno-occlusive disease)..$^{19,93,94,97-99,112}$

Recently, it has become evident that high pulmonary artery pressures may reflect a selective vasoconstriction within the pulmonary arterioles that actually serve to protect capillaries within the dorsocaudal lung regions that would otherwise rupture. Thus, conditions such as inclined running and 80 ppm NO inhalation that lowers pulmonary artery pressures exacerbate EIPH severity. ${ }^{2,66,148}$ In this regard, it would be extremely valuable to define the role played by different segments of the pulmonary vasculature in EIPH, especially as this relates to their structure and vasomotor control, and potentially, changes thereof with repeated EIPH episodes within and across racing seasons. In this regard, the studies of Stack et al particularly on the pulmonary venules and veins may prove to be extremely insightful. ${ }^{93,94,96-99}$

In terms of therapeutic countermeasures that have scientifically proven efficacy in reducing but not abolishing EIPH, furosemide is by far the most widely used (Figure 8). Given the likelihood that furosemide will be banned in North America as a race-day drug in the near future, there is an urgent need for an effective alternative. At present, perhaps, the best candidate for race-day alleviation of EIPH is the nasal strip (Figure 9), use of which is gaining in popularity. Resistance to use of the nasal strip as an alternative to furosemide in the racing industry has likely resulted from the overarching fact that, without the $\sim 20 \mathrm{~kg}$ weight loss from furosemide-induced diuresis, nasal strips (or other countermeasures) do not increase performance sufficiently, or at least 
not to the extent that furosemide does. At present, there is a pressing need for large-scale field trials of the nasal strip ideally using BAL to measure reductions in EIPH severity. In addition, given the hopeful (albeit small scale) results of immunomodulation therapy and conjugated estrogens these putative therapeutic avenues are deserving of closer scientific scrutiny (Figure 11). Resolution of therapeutic efficacy is, to a great extent, contingent on an accurate and sensitive method to quantify EIPH. At present, the more invasive but sensitive BAL is far better than endoscopy but more challenging to build into field studies. However, in the absence of a better method, effective progress in EIPH reduction/prevention may be contingent on wider use of BAL in the field. For EIPH mitigation, strategies incorporating longer race-race intervals, investigating dehydration strategies (to mimic the plasma volume/weight loss and lower pulmonary vascular pressures of furosemide), and in the longer term, selective breeding programs based upon deselecting for $\mathrm{EIPH}^{26}$ are worthy of serious consideration and investigation.

\section{Disclosure}

The authors report no conflicts of interest in this work.

\section{References}

1. Erickson HH. A review of exercise-induced pulmonary hemorrhage and new concepts for prevention. Proc Ann Conv Am Assoc Equine Pract. 2000;46:193-196.

2. Erickson HH, Poole DC. Exercise-induced pulmonary hemorrhage: current concepts. In: Lekeux P, editor. Equine Respiratory Diseases. Ithaca, NY: International Veterinary Information Services; 2007.

3. Poole DC, Epp TS, Erickson HH. Science Overview. Exercise-induced pulmonary haemorrhage (EIPH): mechanistic bases and therapeutic interventions. Equine Vet J. 2007;39(4):292-293.

4. Moran G, Folch H. Exercise-induced pulmonary hemorrhage in horses - review. Acta Vet Brno. 2013;82(3):309-316.

5. West JB. Fragility of pulmonary capillaries. J Appl Physiol. 2013;115(1):1-15.

6. Sullivan S, Hinchcliff K. Update on exercise-induced pulmonary hemorrhage. Vet Clin North Am Equine Pract. 2015;31(1):187-198.

7. Hinchcliff KW, Couetil LL, Knight PK, et al. Exercise induced pulmonary hemorrhage in horses: American College of Veterinary Internal Medicine consensus statement. JVet Intern Med. 2015;29(3):743-758.

8. Epp TS, Szladovits B, Buchannan A, et al. The presence and severity of exercise-induced pulmonary hemorrhage in racing Greyhounds. Comp Exerc Physiol. 2008;5:21-32.

9. Hopkins SR, Schoene RB, Henderson WR, Spragg RG, Martin TR, West JB. Intense exercise impairs the integrity of the pulmonary blood-gas barrier in elite athletes. Am J Respir Crit Care Med. 1997;155(3):1090-1094.

10. Ko YC, Dai MP, Ou CC. Playing saxophone induced diffuse alveolar hemorrhage: a case report. Ir J Med Sci. 2010;179(1):137-139.

11. Léguillette R, Steinmann M, Bond SL, Stanton B. Tracheobronchoscopic assessment of exercise-induced pulmonary hemorrhage and airway inflammation in barrel racing horses. J Vet Intern Med. 2016;30(4):1327-1332.

12. Epp TS, McDonough P, Padilla DJ, et al. Exercise-induced pulmonary haemorrhage during submaximal exercise. Equine Vet J Suppl. 2006;(36):502-507.
13. Lyle CH, Uzal FA, McGorum BC, et al. Sudden death in racing Thoroughbred horses: an international multicentre study of post mortem findings. Equine Vet J. 2011;43(3):324-331.

14. Gunson DE, Sweeney CR, Soma LR. Sudden death attributable to exercise-induced pulmonary hemorrhage in racehorses: nine cases (1981-1983). J Am Vet Med Assoc. 1988;193(1):102-106.

15. Hinchcliff KW, Jackson MA, Morley PS, et al. Association between exercise-induced pulmonary hemorrhage and performance in Thoroughbred racehorses. J Am Vet Med Assoc. 2005;227(5):768-774.

16. Erickson HH, McAvoy JL, Westfall JA. Exercise-induced changes in the lung of Shetland ponies: ultrastructure and morphometry. J Submicrosc Cytol Pathol. 1997;29(1):65-72.

17. Pascoe JR. Exercise-induced pulmonary hemorrhage: a unifying concept. Proc Annu Conv Am Assoc Equine Pract. 1996;42:220-226.

18. Roberts $\mathrm{CA}$, Erickson HH. Exercise-induced pulmonary haemorrhage workshop. Equine Vet J Suppl. 1999;(30):642-644.

19. Robinson NE, Williams KJ, Stack A, Jackson WF, Derksen FJ. Exercise-induced pulmonary haemorrhage: a progressive disease affecting performance? Equine Vet J. 2015;47(3):339-340.

20. Markham G. Markham's Masterpiece Revived: Containing all Knowledge Belonging to the Smith. London: John Richardson for Tho. Passinger; 1688.

21. Youatt W. The Horse. London: Longmans, Green, and Co.; 1874.

22. Robertson JB. Biological searchlight on racehorse breeding: VI. The heredity of blood-vessel breaking in the Thoroughbred. Bloodstock Breeders Rev. 1913;2:265-281.

23. Sullivan SL, Anderson GA, Morley PS, Hinchcliff KW. Prospective study of the association between exercise induced pulmonary hemorrhage and long term performance in Thoroughbred racehorses. Equine Vet J. 2015;47(3):350-357.

24. Sullivan SL, Whittem T, Morley PS, Hinchcliff KW. A systematic review and meta-analysis of the efficacy of furosemide for exerciseinduced pulmonary haemorrhage in Thoroughbred and Standardbred racehorses. Equine Vet J. 2015;47(3):341-349.

25. Morley PS, Bromberek JL, Saulez MN, Hinchcliff KW, Guthrie AJ. Exercise-induced pulmonary haemorrhage impairs racing performance in Thoroughbred racehorses. Equine Vet J. 2015;47(3):358-365.

26. Velie BD, Raadsma HW, Wade CM, Knight PA, Hamilton NA. Heritability of epistaxis in the Australian Thoroughbred racehorse population. Vet J. 2014;202(2):274-278.

27. Preston SA, Riggs CM, Singleton MD, Troedsson MH. Descriptive analysis of longitudinal endoscopy for exercise-induced pulmonary haemorrhage in Thoroughbred racehorses training and racing at the Hong Kong Jockey Club. Equine Vet J. 2015;47(3):366-371.

28. Harvey W. Exercitatio Anatomica de Motu Cordis et Sanguinis in Anamalibus [An Anatomical Disquisition on the Motion of the Heart and Blood in Animals]. Frankfurt: Guilielmi Fitzeri; 1628. Latin.

29. Malpighi M. De Pulmonibus [Lungs]. London: Philosophical Transactions of the Royal Society; 1661. Latin.

30. West JB. Marcello Malpighi and the discovery of the pulmonary capillaries and alveoli. Am J Physiol Lung Cell Mol Physiol. 2013;304(6):L383-L390.

31. Low FN. Electron microscopy of the rat lung. Anat Rec. 1952; 113(4):437-444.

32. Low FN. The pulmonary alveolar epithelium of laboratory mammals and man. Anat Rec. 1953;117(2):241-263.

33. Wood P. An appreciation of mitral stenosis. I. Clinical features. $\mathrm{Br}$ Med J. 1954;1(4870):1051-1063.

34. Wood P. An appreciation of mitral stenosis. II. Investigations and results. Br Med J. 1954;1(4871):1113-1124.

35. Caulfield JB, Borg TK. The collagen network of the heart. Lab Invest. 1979;40(3):364-372.

36. Borg TK, Caulfield JB. Morphology of connective tissue in skeletal muscle. Tissue Cell. 1980;12(1):197-207.

37. Wagner PD, Gale GE, Moon RE, Torre-Bueno JR, Stolp BW, Saltzman HA. Pulmonary gas exchange in humans exercising at sea level and simulated altitude. J Appl Physiol. 1986;61(1):260-270. 
38. Pascoe JR, Ferraro GL, Cannon JH, Arthur RM, Wheat JD. Exerciseinduced pulmonary hemorrhage in racing Thoroughbreds: a preliminary study. Am J Vet Res. 1981;42(5):703-707.

39. Whitwell KE, Greet TRC. Collection and evaluation of tracheobronchial washes in the horse. Equine Vet J. 1984;16(6):499-508.

40. Poole DC, Erickson HH. Highly athletic terrestrial mammals: horses and dogs. Compr Physiol. 2011;1(1):1-37.

41. Erickson BK, Erickson HH, Coffman JR. Pulmonary artery, aortic and oesophageal pressure changes during high-intensity treadmill exercise in the horse: a possible relation to exercise induced pulmonary haemorrhage. Equine Vet J Suppl. 1990;(9):47-52.

42. Erickson BK, Erickson HH, Coffman JR. Pulmonary artery, aortic and oesophageal pressure changes during high-intensity treadmill exercise in the horse; effect of frusemide and phentolamine. Equine Vet J. 1992;24(3):215-219.

43. Jones JH, Smith BL, Tyler WS, et al. Why do horses bleed? Source and cause of exercise-induced pulmonary hemorrhage in horses. In: Clark AE, editor. Proceedings of the International Exercise Induced Pulmonary Hemorrhage Conference. Guelph: Equine Research Center; 1993:23-24.

44. West JB, Mathieu-Costello O, Jones JH, et al. Stress failure of pulmonary capillaries in racehorses with exercise-induced pulmonary hemorrhage. J Appl Physiol. 1993;75(3):1097-1109.

45. Poole DC, Kindig CA, Fenton G, Ferguson L, Rush BR, Erickson HH. Effects of external nasal support on pulmonary gas exchange and EIPH in the horse. J Equine Vet Sci. 2000;20(9):578-585.

46. Ducharme NG, Hackett RP, Gleed RD, Ainsworth DM, Erb HN, Mitchell LM, Soderholm LV. Pulmonary capillary pressure in horses undergoing alteration of pleural pressure by imposition of various upper airway resistive loads. Equine Vet J Suppl. 1999;(30): 27-33.

47. Cook WR. Epistaxis in the racehorse. Equine Vet J. 1974;6(2):45-58.

48. Cook WR, Williams RM, Kirker-Head CA, Verbridge DJ. Upper airway obstruction (partial asphyxia) as the possible cause of exercise-induced pulmonary hemorrhage in the horse: an hypothesis. Equine Vet Sci. 1988;8(1):11-26.

49. Pascoe JR, Raphel CF. Pulmonary hemorrhage in exercising horses. Comp Cont Educ Pract Vet Suppl. 1982;4:S411-S416.

50. Takahashi T, Hiraga A, Ohmura H, Kai M, Jones JH. Frequency of and risk factors for epistaxis associated with exercise-induced pulmonary hemorrhage in horses: 251609 race starts (1992-1997). J Am Vet Med Assoc. 2001;218(9):1462-1464.

51. Schroter RC, Marlin DJ, Denny E. Exercise-induced pulmonary haemorrhage $(\mathrm{EIPH})$ in horses results from locomotory impact induced trauma - a novel, unifying concept. Equine Vet J. 1998;30(3):186-192.

52. Schroter RC, Leeming A, Denny E, Bharath A, Marlin DJ. Modelling impact-initiated wave transmission through lung parenchyma in relation to the aetiology of exercise-induced pulmonary haemorrhage. Equine Vet J Suppl. 1999;(30):34-38.

53. Hinchcliff KW, Morley PS, Jackson MA, et al. Risk factors for exerciseinduced pulmonary haemorrhage in Thoroughbred racehorses. Equine Vet J Suppl. 2010;(38):228-234.

54. Crispe EJ, Lester GD, Robertson ID, Secombe CJ. Bar shoes and ambient temperature are risk factors for exercise-induced pulmonary haemorrhage in Thoroughbred racehorses. Equine Vet J. 2016;48(4):438-441.

55. Fogarty U. Evaluation of a bronchoalveolar lavage technique. Equine Vet J. 1990;22(3):174-176.

56. Moore BR, Cox JH. Diagnostic use of bronchoalveolar lavage in horses. Equine Pract. 1996;18(5):7-15.

57. Robinson NE, Derksen FJ, Slocombe RF, et al. Bronchoalveolar lavage. In: Huntingdon P, editor. Proceedings of the AEVA (Bain-Fallon Memorial Lectures); In: Proceedings of the American Association of Equine Practitioners, AEEP, Lexington, KY; 1986:6-12.

58. Sweeney CR, Rossier Y, Ziemer EL. Effect of lung site and fluid volume on results of bronchoalveolar lavage fluid analysis in horses. Am JVet Res. 1992;53(8):1376-1379.
59. Fogarty U. A bronchoalveolar lavage technique for routine diagnostic purposes. Equine Vet Educ. 1990;2(2):102-104.

60. McKane SA, Canfield PJ, Rose RJ. Equine bronchoalveolar lavage cytology: survey of Thoroughbred racehorses in training. Aust Vet J. 1993;70(11):401-404.

61. Meyer TS, Fedde MR, Gaughan EM, Langsetmo I, Erickson HH. Quantification of exercise-induced pulmonary haemorrhage with bronchoalveolar lavage. Equine Vet J. 1998;30(4):284-288.

62. Depecker M, Richard EA, Pitel PH, Fortier G, Leleu C, CouroucéMalblanc A. Bronchoalveolar lavage fluid in Standardbred racehorses: influence of unilateral/bilateral profiles and cut-off values on lower airway disease diagnosis. Vet J. 2014;199(1):150-156.

63. Fogarty U, Buckley T. Bronchoalveolar lavage findings in horses with exercise intolerance. Equine Vet J. 1991;23(6):434-437.

65. Langsetmo I, Fedde MR, Meyer TS, Erickson HH. Relationship of pulmonary arterial pressure to pulmonary haemorrhage in exercising horses. Equine Vet J. 2000;32(5):379-384.

66. Kindig CA, Ramsel C, McDonough P, Poole DC, Erickson HH. Inclined running increases pulmonary haemorrhage in the Thoroughbred horse. Equine Vet J. 2003;35(6):581-585.

67. Erickson HH, Epp TS, Poole DC. A review of alternative therapies for EIPH. Proc Am Assoc Equine Pract. 2007;53:68-71.

68. Kindig CA, McDonough P, Fenton G, Poole DC, Erickson HH. Efficacy of nasal strip and furosemide in mitigating exercise-induced pulmonary hemorrhage in Thoroughbred horses. J Appl Physiol. 2001;91(3):1396-1400.

69. Geor RJ, Ommundson L, Fenton G, Pagan JD. Effects of an external nasal strip and frusemide on pulmonary haemorrhage in Thoroughbreds following high-intensity exercise. Equine Vet J. 2001;33(6): 577-584.

70. Erickson HH, Kindig CA, Poole DC. Exercise-induced pulmonary hemorrhage: a new concept for prevention. J Equine Vet Sci. 2000;20(3):164-167.

71. McDonough P, Kindig CA, Hildreth TS, et al. Effect of furosemide and the equine nasal strip on exercise-induced pulmonary hemorrhage and time-to-fatigue in maximally exercising horses. Equine Comp Exerc Physiol. 2004;1(3):177-184.

72. Valdez SC, Nieto JE, Spier SJ, Owens SD, Beldomenico P, Snyder JR. Effect of an external nasal strip on cytological characteristics of bronchoalveolar lavage fluid in Thoroughbred racehorses. J Am Vet Med Assoc. 2004;224(4):558-561.

73. Epp TS, McDonough P, Padilla DJ, Cox JH, Poole DC, Erickson HH. The effect of herbal supplementation on the severity of exerciseinduced pulmonary haemorrhage. Equine Comp Exer Physiol. 2005;2(1):17-25.

75. Goetz TE, Manohar M, Hassan AS, Baker GJ. Nasal strips do not affect pulmonary gas exchange, anaerobic metabolism, or EIPH in exercising Thoroughbreds. J Appl Physiol. 2001;90(6):2378-2385.

76. MacNamara B, Bauer S, Iafe J. Endoscopic evaluation of exerciseinduced pulmonary hemorrhage and chronic obstructive pulmonary disease in association with poor performance in racing Standardbreds. J Am Vet Med Assoc. 1990;196(3):443-445.

77. Lapointe JM, Vrins A, McCarvill E. A survey of exercise-induced pulmonary haemorrhage in Quebec Standardbred racehorses. Equine Vet J. 1994;26(6):482-485.

78. Hillidge CJ, Lane TJ, Johnson EL. Preliminary investigations of exercise-induced pulmonary hemorrhage in racing quarter horses. $J$ Equine Vet Sci. 1984;4(1):21-23.

79. Raphel CF, Soma LR. Exercise-induced pulmonary hemorrhage in Thoroughbreds after racing and breezing. Am J Vet Res. 1982;43(7):1123-1127.

80. Mason DK, Collins EA, Watkins KL. Respiratory system. In: Snow DH, Persson SGB, Rose RJ, editors. Equine Exercise Physiology. Cambridge: Granta Editions; 1983:57-63.

81. Burrell MH. Endoscopic and virologic observations on respiratory disease in a group of young Thoroughbred horses in training. Equine Vet J. 1985;17(2):99-103. 
82. Voynick BT, Sweeney CR. Exercise-induced pulmonary hemorrhage in polo and racing horses. J Am Vet Med Assoc. 1986;188(3):301-302.

83. Mair TS, Stokes CR, Bourne FJ. Cellular content of secretions obtained by lavage from different levels of the equine respiratory tract. Equine Vet J. 1987;19(5):458-462.

84. Derksen FJ, Brown CM, Sonea I, Darien BJ, Robinson NE Comparison of transtracheal aspirate and bronchoalveolar lavage cytology in 50 horses with chronic lung disease. Equine Vet J. 1989;21(1): 23-26.

85. Marlin DJ. Exercise-induced pulmonary haemorrhage: a global review of recent findings. In: Proceedings of the World Equine Airways Symposium and Veterinary and Comparative Respiratory Society, Edinburgh, Scotland, 19-23 July 2001. Canada: World Equine Airways Society; 2001.

86. O'Callaghan MW, Goulden BE. Radiographic changes in the lungs of horses with exercise-induced epistaxis. $N$ Z Vet J. 1982;30(8): 117-118.

87. O'Callaghan MW, Pascoe JR, O'Brien TR, Hornof WJ, Mason DK. Exercise-induced pulmonary haemorrhage in the horse: results of a detailed clinical, post mortem and imaging study: VI. Radiological/ pathological correlations. Equine Vet J. 1987;19(5):419-422.

88. Lekeux P, Art T. The respiratory system: anatomy, physiology, and adaptations to exercise and training. In: Hodgson DJ, Rose RJ, editors. The Athletic Horse: Principles and Practice of Equine Sports Medicine. Philadelphia, PA: WB Saunders Co.; 1994:78-127.

89. Rantanen NW, Byars TD, Hauser ML, Gaines RD. Spontaneous contrast and mass lesions in the hearts of race horses: ultrasound diagnosis - preliminary data. J Equine Vet Sci. 1984;4(5):220-223.

90. Mahoney C, Rantanen NW, DeMichael JA, Kincaid B. Spontaneous echocardiographic contrast in the Thoroughbred: high prevalence in racehorses and a characteristic abnormality in bleeders. Equine Vet J. 1992;24(2):129-133.

91. Marr C. Cardiology of the Horse. London: WB Saunders Co.; 1999.

92. Votion DM, Roberts CA, Marlin DJ, Lekeux PM. Feasibility of scintigraphy in exercise-induced pulmonary haemorrhage detection and quantification: preliminary studies. Equine Vet J Suppl. 1999;(30):137-142.

93. Derksen F, Williams K, Stack A. Exercise-induced pulmonary hemorrhage in horses: the role of pulmonary veins. Compend Contin Educ Vet. 2011;33(4):E6.

94. Stack A, Derksen FJ, Sordillo LM, et al. Effects of exercise on markers of venous remodeling in lungs of horses. Am J Vet Res. 2013;74(9):1231-1238.

95. Bernard SL, Glenny RW, Erickson HH, et al. Minimal redistribution of pulmonary blood flow with exercise in racehorses. J Appl Physiol (1985). 1996;81(3):1062-1070.

96. Pelletier N, Robinson NE, Kaiser L, Derksen FJ. Regional differences in pulmonary artery endothelial function: a role in the site of EIPH? Equine Vet J Suppl. 1995;27(S13):99-103.

97. Stack A, Derksen FJ, Williams KJ, Robinson NE, Jackson WF. Regional heterogeneity in the reactivity of equine small pulmonary blood vessels. J Appl Physiol (1985). 2016;120(6):599-607.

98. Stack A, Derksen FJ, Williams KJ, Robinson NE, Jackson WF. Lung region and racing affect mechanical properties of equine pulmonary microvasculature. J Appl Physiol (1985). 2014;117(4):370-376.

99. Williams KJ, Robinson NE, Defeijter-Rupp H, et al. Distribution of venous remodeling in exercise-induced pulmonary hemorrhage of horses follows reported blood flow distribution in the equine lung. J Appl Physiol (1985). 2013;114(7):869-878.

100. Holcombe SJ, Berney C, Cornelisse CJ, Derksen FJ, Robinson NE. Effect of commercially available nasal strips on airway resistance in exercising horses. Am J Vet Res. 2002;63(8):1101-1105.

101. Holcombe SJ, Cornelisse CJ, Derksen FJ, et al. The effect of FLAIR ${ }^{\mathrm{TM}}$ nasal strips on upper airway mechanics in exercising horses. Proc World Equine Airways Symp and Veterinary and Comparative Respiratory Society. Edinburgh, Scotland, 19-23 July 2001. Canada: World Equine Airways Society; 2001;2:21.
102. Art T, Serteyn D, Lekeux P. Effect of exercise on the partitioning of equine respiratory resistance. Equine Vet J. 1988;20(4):268-273.

103. Di Somma EM, West SN, Wheatley JR, Amis TC. Nasal dilator strips increase maximum inspiratory flow via nasal wall stabilization. Laryngoscope. 1999;109(5):780-784.

104. Manohar M. Right heart pressures and blood-gas tensions in ponies during exercise and laryngeal hemiplegia. Am J Physiol. 1986;251 (1 Pt 2):H121-H126.

105. Manohar M. Blood flow in respiratory muscles during maximal exertion in ponies with laryngeal hemiplegia. J Appl Physiol (1985). 1987;62(1):229-237.

106. Van Erck-Westergren E, Franklin SH, Bayly WM. Respiratory diseases and their effects on respiratory function and exercise capacity. Equine Vet J. 2013;45(3):376-387.

107. Newton JR, Wood JL. Evidence of an association between inflammatory airway disease and EIPH in young Thoroughbreds during training. Equine Vet J Suppl. 2002;(34):417-424.

108. Michelotto PV Jr, Muehlmann LA, Zanatta AL, et al. Pulmonary inflammation due to exercise-induced pulmonary haemorrhage in Thoroughbred colts during race training. Vet J. 2011;190(2):e3-e6.

109. McKane SA, Slocombe RF. Experimental mild pulmonary inflammation promotes the development of exercise-induced pulmonary haemorrhage. Equine Vet J Suppl. 2010;(38):235-239.

110. Derksen FJ, Williams KJ, Uhal BD, et al. Pulmonary response to airway instillation of autologous blood in horses. Equine Vet J. 2007;39(4):334-339.

111. Williams KJ, Derksen FJ, Defeijter-Rupp HL, Robinson NE. Repeated blood instillation into the airway of the horse does not cause pulmonary fibrosis. Equine Vet J. 2011;43(3):354-358.

112. Derksen FJ, Williams KJ, Pannirselvam RR, de Feijter-Rupp H, Steel CM, Robinson NE. Regional distribution of collagen and haemosiderin in the lungs of horses with exercise-induced pulmonary haemorrhage. Equine Vet J. 2009;41(6):586-591.

113. Newton JR, Rogers K, Marlin DJ, Wood JL, Williams RB. Risk factors for epistaxis on British racecourses: evidence for locomotory impactinduced trauma contributing to the aetiology of exercise-induced pulmonary haemorrhage. Equine Vet J. 2005;37(5):402-411.

114. Gross DK, Morley PS, Hinchcliff KW, Wittum TE. Effect of furosemide on performance of Thoroughbreds racing in the United States and Canada. J Am Vet Med Assoc. 1999;215(5):670-675.

115. Hinchcliff KW. Effects of furosemide on athletic performance and exercise-induced pulmonary hemorrhage in horses. $\mathrm{J} \mathrm{Am} \mathrm{Vet} \mathrm{Med}$ Assoc. 1999;215(5):630-635.

116. Bayly WM, Slocombe RF, Schott HC 2nd, Hodgson DR. Effect of intravenous administration of furosemide on mass-specific maximal oxygen consumption and breathing mechanics in exercising horses. Am J Vet Res. 1999;60(11):1415-1422.

117. Zawadzkas XA, Sides RH, Bayly WM. Is improved high speed performance following frusemide administration due to diuresis-induced weight loss or reduced severity of exercise-induced pulmonary haemorrhage? Equine Vet J Suppl. 2006;(36):291-293.

118. Erickson HH, Hildreth TS, Poole DC, et al. Management of exerciseinduced pulmonary hemorrhage in non-racing performance horses. Comp Cont Educ Pract Vet. 2001;23:1090-1093.

119. Hinchcliff KW. Management and pharmacotherapy of exercise-induced pulmonary hemorrhage in horses. Proc World Equine Airways Symp. 2001;2:1-10.

120. Erickson HH, Hildreth TS. Novel and emerging therapies for EIPH. Proc Am Coll Vet Intern Med. 2004;22:734-736.

121. Hinchcliff KW, McKeever KH. Frusemide. Equine Vet J Suppl. 1995;(18):256-258.

122. Hinchcliff KW, Hubbell JAE, Grosenbough D. Hemodynamic effects of furosemide are dependent on diuresis. Proc Annu Conv Am Assoc Equine Pract. 1996;42:229-230.

123. Pascoe JR, McCabe AE, Franti CE, Arthur RM. Efficacy of furosemide in the treatment of exercise-induced pulmonary hemorrhage in Thoroughbred racehorses. Am J Vet Res. 1985;46(9):2000-2003. 
124. Sweeney CR, Soma LR. Exercise-induced pulmonary hemorrhage in Thoroughbred horses: response to furosemide or hesperidin-citrus bioflavinoids. J Am Vet Med Assoc. 1984;185(2):195-197.

125. Sweeney CR, Soma LR, Bucan CA, Ray SG. Exercise-induced pulmonary hemorrhage in exercising Thoroughbreds: preliminary results with preexercise medication. Cornell Vet. 1984;74(3):263-268.

126. Sweeney CR, Soma LR, Maxson AD, Thompson JE, Holcombe SJ, Spencer PA. Effects of furosemide on the racing times of Thoroughbreds. Am J Vet Res. 1990;51(5):772-778.

127. Lester G, Clark C, Rice B, Steible-Hartless C, Vetro-Widenhouse T. Effect of timing and route of administration of furosemide on pulmonary hemorrhage and pulmonary arterial pressure in exercising Thoroughbred racehorses. Am J Vet Res. 1999;60(1):22-28.

128. Hopper MK, Pieschl RL Jr, Pelletier NG, Erickson HH. Cardiopulmonary effects of acute blood volume alteration prior to exercise. In: Persson SGB, Lindholm A, Jeffcott LB, editors. Equine Exercise Physiology 3. Davis, CA: ICEEP Publications; 1991:9-16.

129. Olsen SC, Coyne CP, Lowe BS, Pelletier N, Raub EM, Erickson HH. Influence of furosemide on hemodynamic responses during exercise in horses. Am J Vet Res. 1992;53(5):742-747.

130. Manohar M, Hutchens E, Coney E. Pulmonary hemodynamics in the exercising horse and their relationship to exercise-induced pulmonary hemorrhage. Br Vet J. 1993;149(5):419-428.

131. Manohar M, Hutchens E, Coney E. Frusemide attenuates the exercise induced rise in pulmonary capillary blood pressure in horses. Equine Vet J. 1994;26(1):51-54.

132. Gleed RD, Ducharme NG, Hackett RP, et al. Effects of frusemide on pulmonary capillary pressure in horses exercising on a treadmill. Equine Vet J Suppl. 1999;(30):102-106.

133. Erickson HH, Bernard SL, Glenny RW, et al. Effect of furosemide on pulmonary blood flow distribution in resting and exercising horses. J Appl Physiol. 1999;86(6):2034-2043.

134. Chay S, Woods WE, Rowse K, Nugent TE, Blake JW, Tobin T. The pharmacology of furosemide in the horse. V. Pharmacokinetics and blood levels of furosemide after intravenous administration. Drug Metab Dispos. 1983;11(3):226-231.

135. Amis TC, Kirkness JP, di Somma E, Wheatley JR. Nasal vestibule wall elasticity: interactions with a nasal dilator strip. J Appl Physiol (1985). 1999;86(5):1638-1643

136. Harms CA, Wetter TJ, McClaran SR, et al. Effects of respiratory muscle work on cardiac output and its distribution during maximal exercise. J Appl Physiol (1985). 1998;85(2):609-618.

137. Copp SW, Holdsworth CT, Ferguson SK, Hirai DM, Poole DC, Musch TI. Muscle fibre-type dependence of neuronal nitric oxide synthasemediated vascular control in the rat during high speed treadmill running. J Physiol. 2013;591(11):2885-2896.

138. Mónica FZ, Bian K, Murad F. The endothelium-dependent nitric oxide-cGMP pathway. Adv Pharmacol. 2016;77:1-27.

139. Ferguson SK, Hirai DM, Copp SW, et al. Impact of dietary nitrate supplementation via beetroot juice on exercising muscle vascular control in rats. J Physiol. 2013;591(2):547-557.

140. Kindig CA, Gallatin LL, Erickson HH, Fedde MR, Poole DC. Cardiorespiratory impact of the nitric oxide synthase inhibitor L-NAME in the exercising horse. Respir Physiol. 2000;120(2):161-176.

141. Mills PC, Marlin DJ, Scott CM. Pulmonary artery pressure during exercise in the horse after inhibition of nitric oxide synthase. $\mathrm{Br} \mathrm{Vet}$ J. 1996;152:119-122.

142. Manohar M, Goetz TE. L-NAME does not affect exercise-induced pulmonary hypertension in thoroughbred horses. J Appl Physiol (1985). 1998;84(6):1902-1908.

143. Manohar M, Goetz TE. Pulmonary vascular pressures of strenuously exercising Thoroughbreds during intravenous infusion of nitroglycerin. Am J Vet Res. 1999;60(11):1436-1440.
144. Hackett RP, Ducharme NG, Gleed RD, Erb HN, Mitchell LM, Soderholm LV. Oral nitroglycerin paste did not lower pulmonary capillary pressure during treadmill exercise. Equine Vet J Suppl. 1999;(30):153-158.

145. Colahan PT, Jackson CA, Rice B, Szabo N, Jones JH. The effect of sildenafil citrate administration on selected physiological parameters of exercising Thoroughbred horses. Equine Vet J Suppl. 2010;(38):606-612.

146. Mills PC, Marlin DJ, Scott CM, Smith NC. Nitric oxide during exercise and pulmonary disease in the horse. Pferdeheikunde. 1996;12:551-556.

147. Mills PC, Marlin DJ, Demoncheaux E, et al. Nitric oxide and exercise in the horse. J Physiol. 1996;495(Pt 3):863-874.

148. Kindig CA, McDonough P, Finley MR, et al. NO inhalation reduces pulmonary arterial pressure but not hemorrhage in maximally exercising horses. J Appl Physiol (1985). 2001;91(6):2674-2678.

149. Ragland WL, McCullough R, Wilkey WC. Passive immunotherapy of equine respiratory disease: treatment of acutely ill horses with equine immunoglobulin. Equine Athlete. 1995;8(6):16-21.

150. Saulez MN, Godfroid J, Bosman A, et al. Cytokine mRNA expressions after racing at a high altitude and at sea level in horses with exerciseinduced pulmonary hemorrhage. Am J Vet Res. 2010;71(4):447-453.

151. Epp TS, McDonough P, Behnke BJ, et al. The effects of concentrated equine serum on exercise-induced pulmonary hemorrhage in Thoroughbred horses. Equine Comp Exerc Physiol. 2005;2:17-25.

152. Epp TS, McDonough P, Myers DE, et al. The effectiveness of immunotherapy in treating exercise-induced pulmonary haemorrhage. J Equine Vet Sci. 2009;29(6):527-532.

153. Portier K, de Moffarts B, Fellman N, et al. The effects of dietary N-3 and antioxidant supplementation on erythrocyte membrane fatty acid composition and fluidity in exercising horses. Equine Vet J Suppl. 2006;(36):279-284.

154. Maciocia G. The Practice of Chinese Medicine: The Treatment of Diseases with Acupuncture and Chinese Herbs. Edinburgh: Churchill and Livingstone; 1998

155. Xie H. Herbal formulas for respiratory diseases in equine practice. A Course in Traditional Chinese Herbal Medicine: International Veterinary Acupuncture Society. Module. 2001;2:25-27.

156. Bayly WM, Meyers KM, Keck MT, Huston LJ, Grant BD. Effects of furosemide on exercise-induced alterations in haemostasis in Thoroughbred horses exhibiting post-exercise epistaxis. In Snow DH, Persson SGB, Rose RJ, editors. Equine Exercise Physiology. Cambridge: Granta Editions; 1983:64-70.

157. Johnstone IB, Viel L, Crane S, Whiting T. Hemostatic studies in racing Standardbred horses with exercise-induced pulmonary hemorrhage. Hemostatic parameters at rest and after moderate exercise. Can J Vet Res. 1991;55(2):101-106.

158. Giordano A, Meazza C, Salvadori M, Paltrinieri S. Thromboelastometric profiles of horses affected by exercise-induced pulmonary hemorrhages. Vet Med Int. 2010;2010:945789.

159. Heidmann P, Tornquist SJ, Qu A, Cebra CK. Laboratory measures of hemostasis and fibrinolysis after intravenous administration of epsilonaminocaproic acid in clinically normal horses and ponies. Am J Vet Res. 2005;66(2):313-318.

160. Epp TS, Edwards KL, Poole DC, Erickson HH. Effects of conjugated estrogens and aminocaproic acid upon exercise-induced pulmonary hemorrhage. Comp Exerc Physiol. 2008;5(2):95-103.

161. Buchholz BM, Murdock A, Bayly WM, Sides RH. Effects of intravenous aminocaproic acid on exercise-induced pulmonary haemorrhage (EIPH). Equine Vet J Suppl. 2010;(38):256-260.

162. Elliott AR, Fu Z, Tsukimoto K, Prediletto R, Mathieu-Costello O, West JB. Short-term reversibility of ultrastructural changes in pulmonary capillaries caused by stress failure. J Appl Physiol (1985). 1992;73(3):1150-1158. 
Veterinary Medicine: Research and Reports is an international, peer-reviewed, open access journal publishing original research, case reports, editorials, reviews and commentaries on all areas of veterinary medicine. The manuscript management system is completely online and includes a very quick and fair peer-review system.
Visit http://www.dovepress.com/testimonials.php to read real quotes from published authors.

Submit your manuscript here: http://www.dovepress.com/veterinary-medicine-research-and-reports-journal 